\title{
Evaluation of the impact of leucocytospermia on semen oxidative status by chemiluminescence technique in infertile men"
}

\author{
Afifa Sellami ${ }^{1,2 \# \dagger}$, Nozha Chakroun ${ }^{1,2 \#}$, Yemna Rtaib ${ }^{1,2}$, Hajer Hdhili ${ }^{1,2}$, Riadh Ben Mansour ${ }^{3}$, \\ Louati Dolira $^{4}$, Kais Chaabene ${ }^{4}$, Leila Keskes ${ }^{1}$, Saloua Lassoued ${ }^{3}$, Tarek Rebai ${ }^{1,2}$ \\ ${ }^{1}$ Laboratory of Histology and Biology of Reproduction, Medical School, Sfax, Tunisia \\ ${ }^{2}$ Histology Embryology Research Unit, Medical School, Sfax, Tunisia \\ ${ }^{3}$ Laboratory of Cell Culture, Biotechnology Institute, Sfax, Tunisia \\ ${ }^{4}$ Gynaecology and Obstetrics Department, Hedi Chaker Academic Hospital, Sfax, Tunisia \\ Email: ‘sellamiafifa@yahoo.fr, nozhafeki@yahoo.fr
}

Received 9 September 2013; revised 10 October 2013; accepted 26 October 2013

Copyright (C) 2013 Afifa Sellami et al. This is an open access article distributed under the Creative Commons Attribution License, which permits unrestricted use, distribution, and reproduction in any medium, provided the original work is properly cited.

\begin{abstract}
The presence of high reactive oxygen species (ROS) levels in semen is a major factor involved in the decline of male fertility. In seminal plasma, ROS are mainly produced by activated leucocytes. Spermatozoa were the first cell type reported to show a potential susceptibility to oxidative damage. The aim of our study was to evaluate the impact of leucocytospermia on basal and FMLP (Formyl-MethionylLeucyl-Phenylalanine) induced oxidative status in semen of infertile men. We also analyzed the correlations of the spermatic parameters with amounts of ROS in semen. Our study included 50 semen samples of infertile men. Sperm analysis was performed using WHO standardized method. Seminal leucocytes were quantified using peroxidase technique. The measurement of ROS levels in semen was made by chemiluminescence assay. We measure respectively ROS amounts in neat semen and in washed sperm cells suspension from the same ejaculate. We also applied the test of provocation of leucocytes by FMLP on neat and washed samples to assess the spermatic oxidative status after leucocyte stimulation. Our results showed significant correlations between ROS levels in neat semen and many sperm parameters: motility, sperm concentration, leucocytes concentration and the rate of sperm cytoplasmic droplets. The studied samples were divided into 2 groups: (G1) composed of 36 samples without leucocytospermia and (G2) composed of 14 leucospermic samples. ROS levels were

\footnotetext{
*Disclosure: The authors declare that there are no conflicts of interest.

\#The first two authors contribute equally to the article.

${ }^{\dagger}$ Corresponding author.
}

significantly lower in G1 than in G2 $(p=0.002)$. ROS production was significantly increased after application of FMLP in washed leucospermic samples ( $p=$ 0.001 ). The measurement of ROS in neat semen is a considerable contribution to explore the impairment of semen quality in infertile men. ROS levels in washed semen reflect the oxidative status generated by sperm preparation techniques used in assisted reproductive procedures. Levels of ROS are highly influenced by the presence of leucocytes and associated with decreased seminal parameters.

Keywords: Semen; Oxidative Stress; Leucocytospermia; Chemiluminescence; ROS; FMLP

\section{INTRODUCTION}

Oxidative stress induced by reactive oxygen species (ROS) plays crucial roles in a wide range of physiological processes and is also implicated in various diseases, such as cancer, cardiovascular pathology, neurodegenerative disorders, and other chronic conditions [1,2]. In semen, the controlled generation of very low amounts of ROS appears to regulate sperm normal functions $[3,4]$. Oxidative stress appears in semen once an imbalance between the production of ROS and their destruction by different enzymatic and non-enzymatic seminal antioxidant systems is created [5]. Interestingly, spermatozoa were the first cell type reported to show a potential susceptibility to oxidative damage [6]. While the presence of high levels of ROS in the ejaculate is among the risk factors involved in reducing male fertility $[7,8]$. It has evolved that three inter-related mechanisms account for 
oxidative stress-mediated male infertility: impaired motility, impaired fertilization and oxidative DNA damage $[9,10]$.

The principle sources of excessive generation of ROS in semen are activated leucocytes and abnormal spermatozoa $[11,12]$. Indeed, the prevalence of leucocytospermia in infertile men varies from $2 \%$ to $40 \%$ depending on the patient population, the detection method and threshold values used [13]. Moreover, it has been shown that depending on their activation status, leucocytes are capable of producing ROS and cytokines and there seems to be a relation between ROS formation and cytokine production $[14,15]$.

The importance of seminal ROS production has been already stressed in the World Health Organization manuals (WHO 1999 and WHO 2010) [16,17]. The chemiluminescence method is the most commonly employed technique as a direct measurement of ROS generation in semen according to the standardized method recommended by the WHO 1999 [16]. This assay is capable of quantifying both intracellular and extracellular ROS [18]. Furthermore, the use of leukocyte-specific stimulant (FMLP: formyl-methionyl-leucyl-phenylalanine) can enhance the chemiluminescent signal to measure low amounts of light generated by leucocytes $[16,19]$.

The degree of sperm damage by leucocytes products depends on the location of the inflammatory reaction, the duration of exposure of sperm to these products and the ability of spermatozoa to activate its intrinsic anti-lipoperoxidative defense systems [20]. The clinical signifycance of both ROS and leucocytes levels continues to be debated. Some authors have found ROS levels or leukocyte counts to be of little prognostic help in either in vivo or in vitro reproduction [21]. These findings are in disagreement with other in vivo [22] and in vitro studies $[19,23]$ that reported the significant prognostic value of semen ROS levels in reproduction. Much of the controversy centers on the best definition of pathological leucocytospermia and the correlation of leucocytes with seminal oxidative stress are unclear $[15,24,25]$.

The aims of our study were to evaluate the impact of leucocytospermia on basal and FMLP induced semen oxidative status using the chemiluminescence technique in infertile men. We also analyzed the correlations of the routine spermatic parameters with amounts of ROS generation in semen.

\section{MATERIAL AND METHODS}

\subsection{Patients}

Our study was carried out in 50 semen samples from male partner of infertile couple attending the HistologyEmbryology laboratory of Sfax medical school (Tunisia) for semen investigations. The patients were aged be- tween 27 and 51 years old with a mean age $( \pm$ Standard Deviation (SD)) of $36.16 \pm 0.57$ years.

\subsection{Collection of Semen Samples}

Semen samples were collected by masturbation after 3 5 days of sexual abstinence and allowed to liquefy for 30 minutes at $37^{\circ} \mathrm{C}$.

\subsection{Semen Analysis}

Basic semen analysis consisted in the measurement of the following semen parameters: volume, sperm concentration, percentage of motile spermatozoa, sperm vitality and percentage of normal spermatozoa. For sperm concentration, diluted semen samples were mixed before transferring a drop to the chamber of the hemocytometer. The spermatozoa were counted under a light microscope at $400 \times$ magnification. To determine the percentage of motile spermatozoa, a $10 \mu \mathrm{l}$ drop of mixed semen was placed on a heated glass slide $\left(37^{\circ} \mathrm{C}\right)$ under a square cover glass $(22 \mathrm{~mm})$ and observed at $400 \times$ magnification. The percentage of motile spermatozoa was evaluated immediately and four hours after semen liquefaction, we evaluated total motility, rapid progressive motility (type a), slow progressive motility (type b), and no progressive motility (type c) according to WHO guidelines [16]. Sperm vitality was assessed using eosin-nigrosin staining technique. A $20 \mu \mathrm{l}$ of liquefied semen was mixed with $20 \mu \mathrm{l}$ of eosin (1\%) and $20 \mu \mathrm{l}$ of nigrosin $(10 \%)$. The suspension was incubated for $30 \mathrm{~s}$ at room temperature. Then, a $20 \mu \mathrm{l}$ of the solution was smeared on a microscope slide. The smear was air dried and examined at $1000 \times$ magnification under oil immersion. Unstained sperm (white) were classified as viable and those that showed any pink or red coloration were classified as dead. Sperm morphology was assessed in Shorr-stained semen smears. All parameters were carried out according to the standardized methods recommended by the WHO [16].

\subsection{Assessment of Leucocytes in Semen by Peroxidase Method}

A leukocyte count was carried out by using the cytochemical peroxidase method, as described in the WHO laboratory manual [16]. This assay identifies polymorphonuclear granulocytes, the most prevalent leucocyte type in semen, as peroxidase-positive cells. A working solution was prepared by combining $250 \mu \mathrm{l}$ of Benzidine with $50 \mu \mathrm{l}$ of Hydrogen peroxide $\left(\mathrm{H}_{2} \mathrm{O}_{2}\right)$. The procedure consisted of mixing $50 \mu 1$ of neat semen with $50 \mu 1$ of the working solution. This mixture was allowed for $30 \mathrm{~min}-$ utes at room temperature. We transferred $20 \mu \mathrm{l}$ of the mixture onto a hemocytometer chamber and the number of peroxidase-positive leucocytes which stained brown 
was counted at $400 \times$ magnification. Leucocytospermia was defined as the presence of more than $1 \times 10^{6}$ leucocytes per milliliter of semen [16].

\subsection{Semen Preparation}

From each sample, one aliquot of $0.5 \mathrm{ml}$ of liquefied neat semen was used for immediate ROS measurement and another $0.5 \mathrm{ml}$ aliquot of semen was centrifuged at $300 \mathrm{~g}$ for 7 minutes. Seminal plasma was removed and the pellet of cells was washed twice in $3 \mathrm{ml}$ of PBS (Phosphate Buffer Saline, isotonic solution, $\mathrm{pH}=7.4$ ). The supernatant was then removed and the cells pellet was suspended in a volume of $0.5 \mathrm{ml}$ of PBS. Sperm concentration in the final solution was evaluated before ROS measurement.

\subsection{Measurement of Reactive Oxygen Species (ROS) in Semen by Chemiluminescence Technique}

The measurement of ROS in semen was made by chemiluminescence using a microplate luminometer (Luminoskan Ascent, Thermo Electron Corporation). Chemiluminescence probe used is luminol (5-amino-2, 3-dihydro 1, 4-phthalazinedione; Sigma chemical Co) which is a redox-sensitive, light emitting probe [26]. A $10 \mathrm{mM}$ stock solution of Luminol was prepared in DMSO (Dimethyl Sulfoxide; Sigma-Aldrich). For each semen sample, we measured the basal levels of ROS in neat semen and in a suspension of washed semen cells obtained from the same ejaculate.

The basal ROS production was measured respectively in $200 \mu \mathrm{l}$ of liquefied neat semen and $200 \mu \mathrm{l}$ of washed cells suspension after addition of $5 \mu \mathrm{l}$ of the working solution of Luminol $(0.1 \mathrm{mM})$ obtained by dilution of the stock solution with the HBSS (Hank's Balanced Salt Solution). Negative controls for estimation of background signals were prepared for each assay by adding 5 $\mu 1$ of $0.1 \mathrm{mM}$ Luminol to $200 \mu \mathrm{l}$ of PBS. Also, $200 \mu \mathrm{l}$ of PBS served as a blank.

We also applied the test of specific provocation of leucocytes by FMLP (Formyl-Methionyl-Leucyl-Phenylalanine; Sigma Aldrich) on all our samples (neat and washed). The FMLP is used to stimulate a chemiluminescent signal from any polymorphonuclear granulocytes that are present in the sperm suspension [16]. Since FMLP receptors are not present on the surface of human spermatozoa, this signal is specific for the leucocyte population [16]. A $0.1 \mathrm{mM}$ stock solution of FMLP in DMSO was prepared.

The ROS production was measured respectively in $200 \mu \mathrm{l}$ of liquefied neat semen and $200 \mu \mathrm{l}$ of washed cells suspension after addition of $5 \mu \mathrm{l}$ of the working solution of Luminol $(0.1 \mathrm{mM})$ and stimulation with $2 \mu 1$ of FMLP working solution $(0.2 \mu \mathrm{M})$ obtained by dilution of the FMLP stock solution with the HBSS. The chemiluminescence signal was monitored for 15 minutes. Results were expressed as relative light units (RLU) per minute and per $20 \times 10^{6}$ spermatozoa.

\section{STATISTICAL ANALYSIS}

A statistical analysis was performed using SPSS 13.0 software. Statistical tests including Student's t test, Pearson's and Spearman's correlations, linear regression were used. The statistical significance was considered for $\mathrm{p}$ values $<0.05$.

\section{RESULTS}

The mean values $( \pm \mathrm{SD})$ and ranges of semen parameters, basal and after FMLP stimulation ROS levels in neat and washed semen are summarized in Table 1.

The levels of basal ROS in neat semen was negatively correlated with the immediate and late total motility, the immediate and late rapid progressive motility and the sperm concentration (Table 2; Figures 1(a)-(c)). We also found significant and positive correlations of levels of basal ROS in neat semen with the leucocytes concentration in semen firstly and with the rates of cytoplasmic droplets in the mid piece area of spermatozoa secondly (Table 2; Figures 1(d) and (e)).

There was a marked increase of ROS in semen after washing (Table 1) with significant correlations of the

Table 1. Means and ranges of semen parameters, basal ROS levels in neat and washed semen and ROS levels in neat and washed semen after FMLP stimulation $(\mathrm{n}=50)$.

\begin{tabular}{|c|c|c|}
\hline & Means \pm SD & Ranges \\
\hline Volume (ml) & $3.9 \pm 1.5$ & $1.9-8.5$ \\
\hline Total motility (\%) & $38.7 \pm 14.6$ & $0-60$ \\
\hline $\begin{array}{l}\text { Rapid progressive mobility "a" } \\
\text { (\%) }\end{array}$ & $10.6 \pm 7.1$ & $0-25$ \\
\hline $\begin{array}{l}\text { Sperm concentration } \\
\text { (Millions } / \mathbf{m l} \text { ) }\end{array}$ & $45.9 \pm 39.8$ & $0.02-189.6$ \\
\hline Vitality (\%) & $68.9 \pm 14.9$ & $26-89$ \\
\hline Leucocytes (millions/ml) & $0.9 \pm 2.1$ & $0.01-9.5$ \\
\hline Normal morphology (\%) & $7.2 \pm 5.3$ & $0-22$ \\
\hline Cytoplasmic droplets (\%) & $5.1 \pm 4.9$ & $0-20$ \\
\hline \multicolumn{3}{|l|}{ Basal ROS (RLU/mn/ 20.10 $\left.{ }^{6} \mathrm{spz}\right)$} \\
\hline In neat semen & $3.9 \pm 21.4$ & $0.01-150.5$ \\
\hline In washed semen & $164.6 \pm 1136.2$ & $0.03-8037$ \\
\hline \multicolumn{3}{|l|}{$\begin{array}{l}\text { ROS after FMLP stimulation } \\
\left(\text { RLU } / \mathbf{m n} / 20 \times 10^{6} \mathrm{spz}\right)\end{array}$} \\
\hline In neat semen & $3.9 \pm 21.7$ & $0.01-153.0$ \\
\hline In washed semen & $222.7 \pm 1542.7$ & $0.02-10912.5$ \\
\hline
\end{tabular}




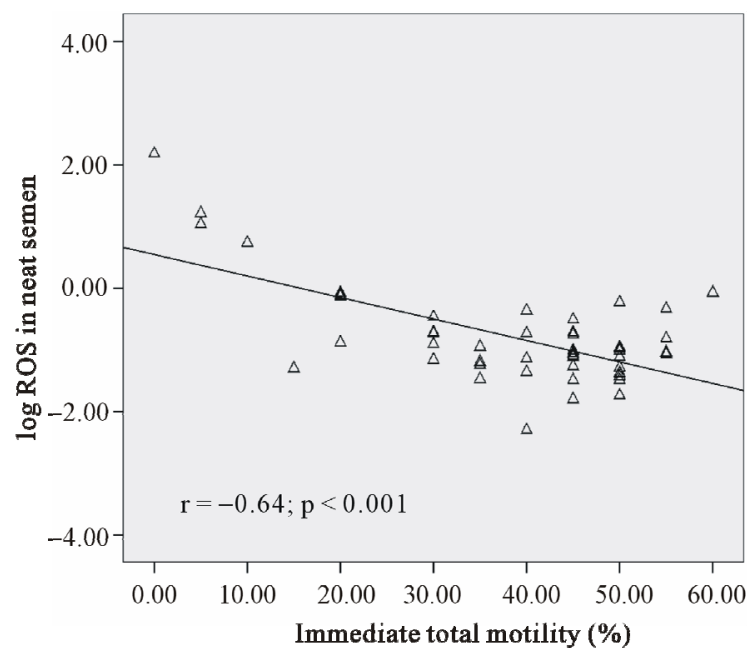

(a)

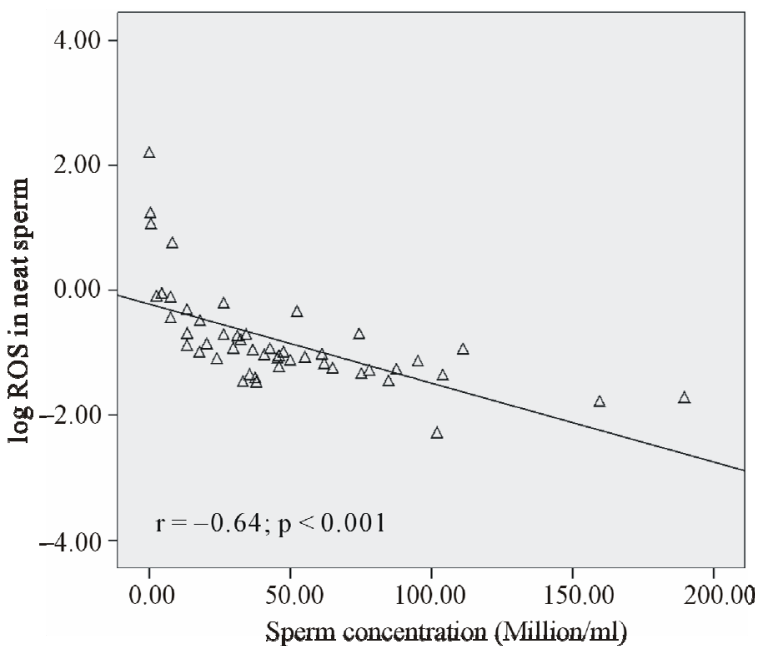

(c)

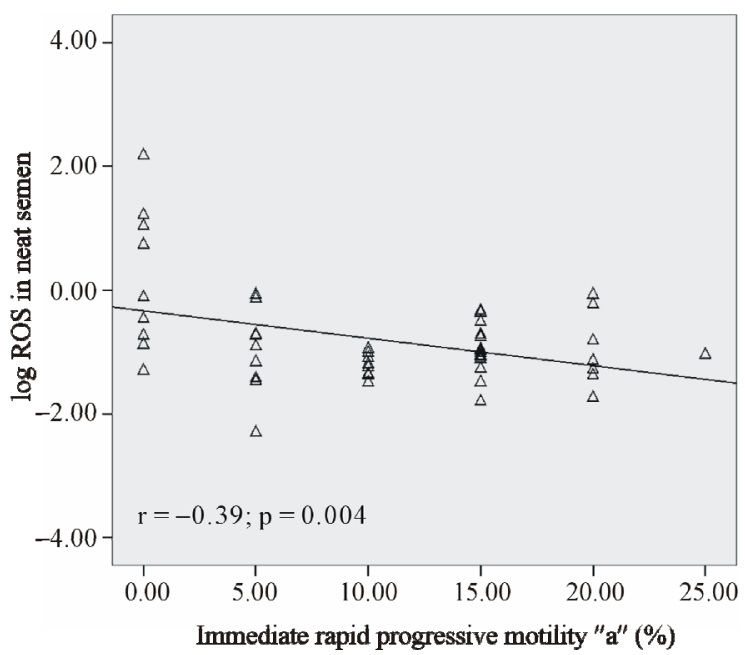

(b)

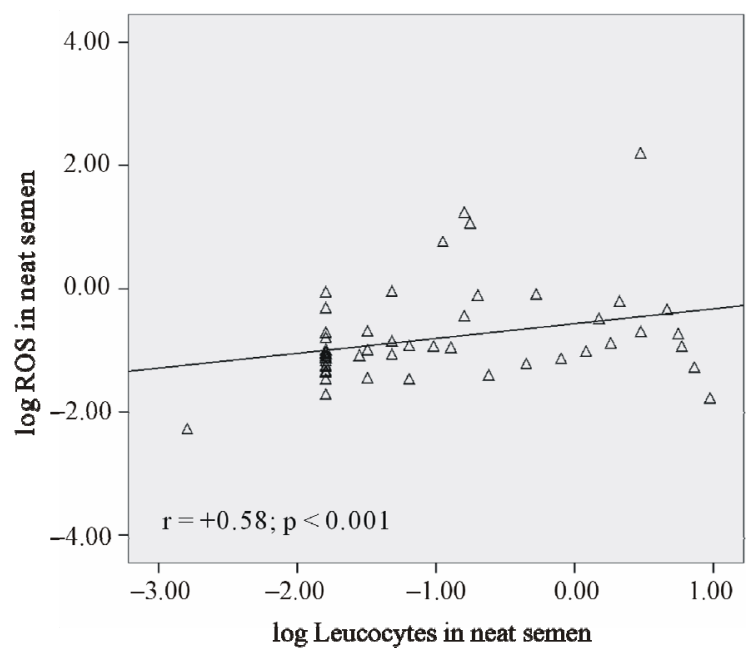

(d)

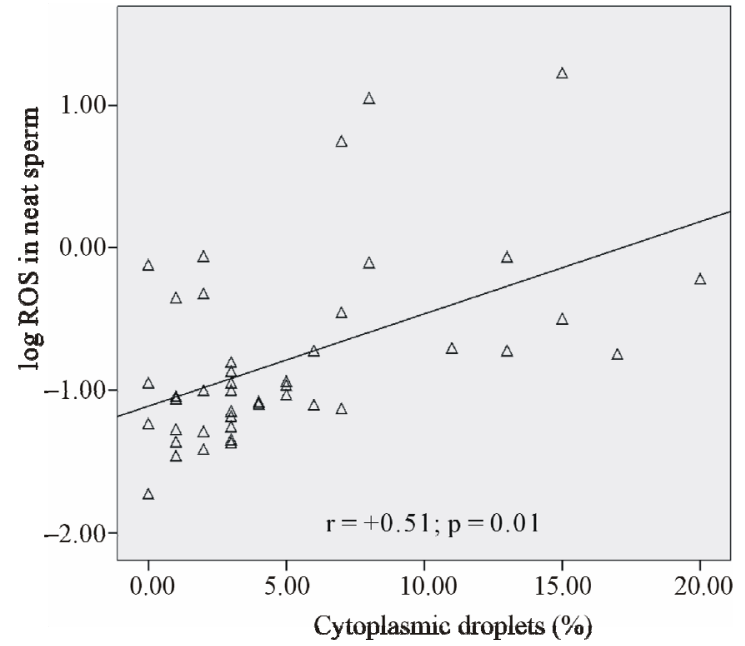

(e)

Figure 1. Correlations of basal ROS levels (log transformed) in neat semen with the following semen parameters: immediate total motility (a), immediate progressive motility (b), sperm concentration (c), leucocyte concentration (d), and cytoplasmic droplets (e). Empirical distributions of the ROS levels were highly skewed on the original scale, and so log-transformed data were used for all statistical analyzes. Basal ROS in neat semen was positively correlated with the leucocytes concentration in semen and with the rates of cytoplasmic droplets in the mid piece area of spermatozoa. 
ROS levels in neat semen with those in sperm suspension after washing (Figure 2).

The studied samples were divided into 2 groups: (G1) composed of 36 samples without leucospermia (leucocytes $<10^{6} / \mathrm{ml}$ and (G2) composed of 14 leucospermic samples (leucocytes $\geq 10^{6} / \mathrm{ml}$ ). ROS levels were signifycantly higher in the group of leucospermic samples compared with the group of leucocyte free samples (Table 3) and a significant and positive correlation of basal

Table 2. Correlations between ROS levels in neat semen and semen parameters $(n=50)$. The levels of basal ROS in neat semen were negatively correlated with the immediate and late total motility, the immediate and late rapid progressive motility and the sperm concentration.

\begin{tabular}{ccc}
\hline & \multicolumn{2}{c}{ ROS in neat semen $(\mathbf{n}=\mathbf{5 0})$} \\
\cline { 2 - 3 } & $\begin{array}{c}\text { Correlation } \\
\text { coefficient }\end{array}$ & P value \\
\hline Sperm concentration & -0.77 & $<0.001$ \\
Immediate total Motility & -0.45 & 0.001 \\
Immediate rapid progressive & -0.27 & 0.04 \\
motility "a" & -0.46 & 0.001 \\
Late total Motility & -0.29 & 0.04 \\
Late rapid progressive motility "a" & +0.02 & $\mathrm{NS}$ \\
Sperm vitality & +0.32 & 0.02 \\
Leucocytes & -0.02 & $\mathrm{NS}$ \\
Sperm morphology & +0.51 & $<0.001$ \\
Cytoplasmic droplets & &
\end{tabular}

NS $=$ No significant. Pearson's and Spearman's correlations tests was used and statistical significance was assessed at $\mathrm{p}<0.05$.

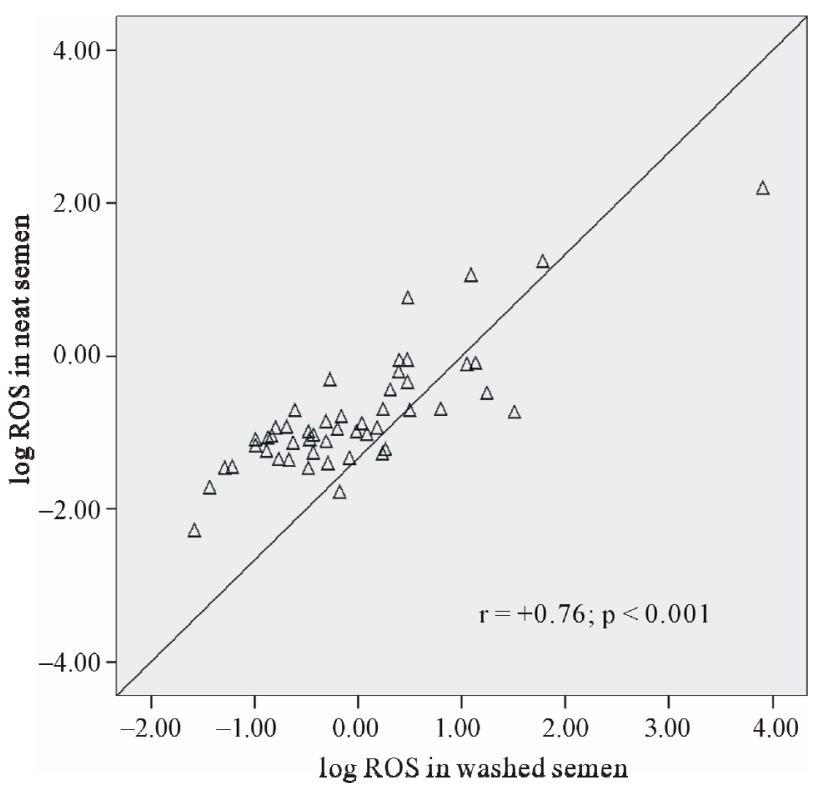

Figure 2. The correlation of basal ROS levels (log transformed) in neat semen with basal ROS levels (log transformed) in washed semen was positively significant.
ROS levels in washed semen with seminal leucocytes concentrations was noted (Figure 3). ROS production was significantly increased after FMLP stimulation in leucospermic washed samples (Figure 4).

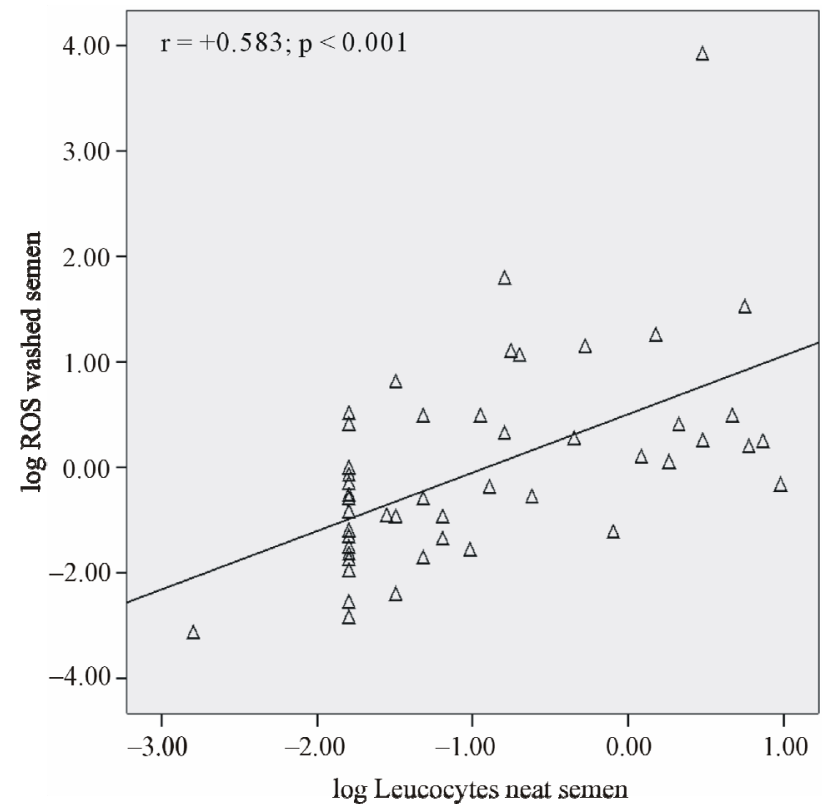

Figure 3. Correlation of basal ROS levels in washed semen with seminal leucocytes concentrations in neat semen. Positive correlation was noted between basal ROS levels (log transformed) in washed semen with seminal leucocytes concentrations (log transformed) in neat semen.

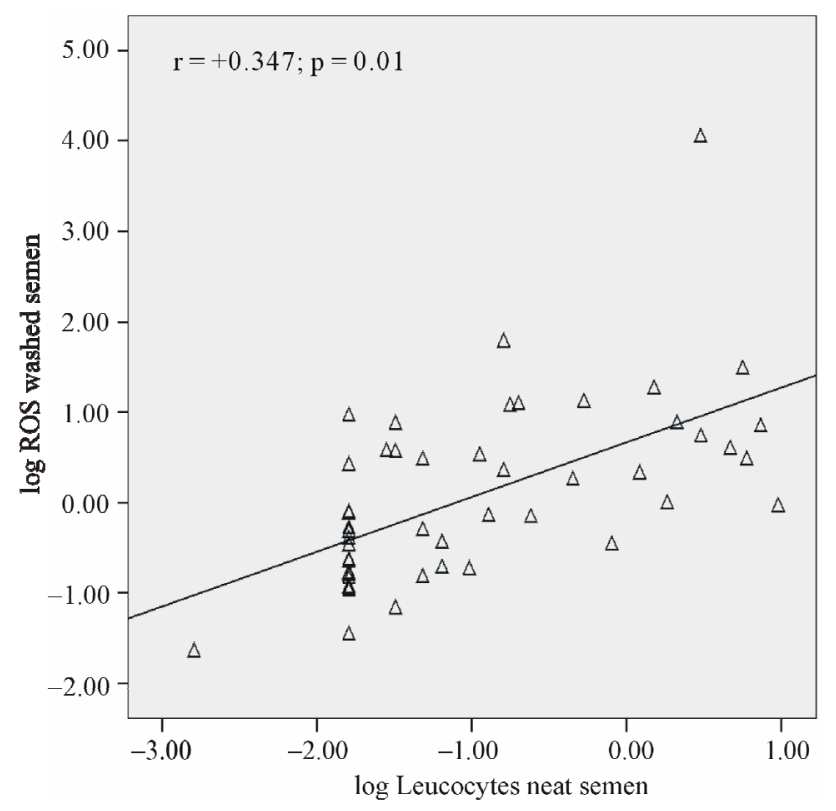

Figure 4. Correlation of FMLP stimulated ROS levels in washed semen with leucocytes concentrations in neat semen. Positive correlation was noted between FMLP stimulated ROS levels (log transformed) in washed semen with leucocytes concentrations (log transformed) in neat semen. 
Table 3. Comparison of semen parameters, basal and FMLP induced semen oxidative status between leucocyte free samples (G1) and leucospermic samples (G2); the ROS levels were significantly enhanced in washed semen and after FMLP application in leucospermic group.

\begin{tabular}{lccc}
\hline & $\begin{array}{c}\text { Means } \pm \text { SD } \\
\text { G1 (n= 36) }\end{array}$ & $\begin{array}{c}\text { Means } \pm \text { SD } \\
\text { G2 (n= 14) }\end{array}$ & P value \\
\hline Volume (ml) & $4.2 \pm 1.6$ & $3.6 \pm 1.2$ & NS \\
Sperm concentration (Millions/ml) & $42.3 \pm 37.4$ & $54.9 \pm 45.6$ & NS \\
Immediate total Motility (\%) & $39.7 \pm 14.3$ & $36.1 \pm 15.6$ & NS \\
Immediate rapid progressive motility “a”, (\%) & $10.4 \pm 6.8$ & $11.1 \pm 7.9$ & NS \\
Late total Motility (\%) & $35.1 \pm 15.8$ & $28.5 \pm 16.5$ & NS \\
Late rapid progressive motility “a" (\%) & $7.7 \pm 6.2$ & $7.3 \pm 6.9$ & NS \\
ROS (RLU/20.106 spz) & & & 0.002 \\
$\quad$ Neat semen FMLP(-) & 1.06 & 10.96 & 0.002 \\
$\quad$ Neat semen FMLP(+) & 0.95 & 11.22 & 0.001 \\
$\quad$ Wasched semen FMLP(-) & 3.12 & 579.72 & 0.001 \\
\hline
\end{tabular}

FMLP (-): without FMLP stimulation; FMLP (+): after FMLP stimulation; NS: No significant. Student's t test was used for comparison and statistical significance was assessed at $\mathrm{p}<0.05$.

\section{DISCUSSION}

It is well established that the production of excessive quantities of reactive oxygen species in the male genital tract, essentially by leucocytes, can overwhelm the seminal antioxidant defenses and give rise to a harmful oxidative stress altering the microenvironment in which spermatozoa develop and mature [5,18,27]. Currently, there are growing evidences that genital oxidative stress is involved in the pathogenesis of many reproductive processes through sperm damage, deformity and eventually male infertility $[28,29]$. We used chemiluminescence technique in our study because it is the most commonly described assay to detect ROS production within semen [30]. It is very sensitive and has the advantage of relatively well established reported ranges for both the fertile and infertile population [31-33].

As regards the relationship between semen quality and its oxidative status evaluated by chemiluminescence assay, we found significant correlations between basal ROS levels produced in neat semen of infertile men and conventional sperm parameters such as motility, sperm concentration and one of sperm morphological abnormalities (cytoplasmic droplets in mid piece area of spermatozoa).

The decrease of sperm motility associated to an oxidative stress in infertile men semen was reported previously [23,34-36] and was related to the negative effect of ROS on sperm mitochondrial membrane potential and the reduction of ATP production [37-39]. In addition, the sperm membranes are characterized by the abundance of unsaturated fatty acids having a double-bonded nature and predisposing them to lipid peroxidation $[26,40]$. This peroxidation reaction affects membrane structure and fluidity and causes damage to axonemal proteins leading to a permanent impairment in sperm motility [41-43].

In the present study, we founded a significant negative correlation between sperm concentration and the levels of ROS in semen. Indeed, it was widely reported that seminal concentrations of ROS in oligospermic patients were higher than that of normospermic patients [31, 44-46]. ROS and their metabolites attack DNA, lipids and proteins, alter enzymatic systems and cell signaling pathways, producing irreparable alterations and may accelerate the process of germ cell apoptosis [47]. The latter process can lead to decline in sperm counts and may explain the apparent deterioration of semen quality [39, 48]. Also, the decrease in the sperm concentration could be explained by the presence of a genital inflammation process which often results in the presence of high number of leucocytes, principle source of ROS in semen $[49,50]$. Indeed, our results showed a significant increase of ROS in leucospermic samples compared with the samples without leucospermia. These results are consistent with other reports indicating that seminal leucocytes have the potential to cause oxidative stress through their degranulation and the formation of free radicals [9]. In fact, it was also reported that the presence of leucocytes in semen is associated with a high rate of production of ROS with reduction of sperm motility and its fertilizing ability [34]. The activation state of leucocytes must play an important role in determining final ROS output [51]. Pro-inflammatory seminal plasma cytokines such as IL-6, IL-8 and tumour necrosis factor TNF $\alpha$ seem to be produced locally by activated leucocytes in semen and a marked relationship between these cytokines, leucocytes and seminal ROS production was 
reported [14,50,52]. During epididymal transit, the sperm are not in contact with seminal plasma antioxidants, and are therefore vulnerable to oxidative damage, especially when there is an epididymal inflammation [49]. It was also demonstrated that leucocytospermia increased the production of ROS by human spermatozoa [53].

The application of a leucocyte-specific stimulant (FMLP) test showed an increase in ROS production especially in semen samples of leucospermic group. Leucocytes are the only cells present in the human ejaculate possessing detectable receptors for FMLP and capable of generating reactive oxygen species in response to this reagent [54]. Our results confirm that leucocytes are the major source of ROS in semen and present an additional argument that the presence of leucocytes in semen is associated with a high rate of production of ROS. Moreover, the results of the FMLP provocation test have an important bearing on the fertileizing capacity of the spermatozoa in vitro $[19,55]$.

The leucocytes are the principle but not the exclusive source of ROS in semen and in concordance with our findings, Aitken [44] and Gomez [56] showed a signifycant production of free radicals by cytosplasmic droplets present at the midpiece of the defective morphologically abnormal spermatozoa. These residues are rich in Glucose-6-phosphate dehydrogenase (G6PD), an enzyme which controls the rate of glucose flux and intracellular production of Nicotinamide Adenine Dinucleotide Phosphate (NADPH) [57]. The latter is used to fuel the generation of ROS via NADPH oxidase located within the sperm membrane [56-58]. As a result, teratozoospermic sperm produce increased amounts of ROS with a reduced antioxidant capacity compared with morphologically normal sperm $[9,59]$. All these relationships underpin the well established observation that higher ROS have a negative impact on sperm quality but even men with normozoospermic idiopathic infertility exhibit significantly higher seminal ROS production and lower antioxidant capacity than fertile men for as yet unknown reasons $[28,60]$.

Besides the measure of ROS level in neat semen, we quantified ROS in semen after washing and removal of seminal plasma. We apply this assay in our study to evaluate the oxidative status of semen during sperm preparation techniques for assisted reproductive technologies. Our results are similar to those reported in other studies [61-63] that showed a significant increase of ROS production in semen by repeated cycles of centrifugation and aggravated by the ablation of the natural antioxidant environment. Some studies [64-66] showed that the addition of antioxidants such as EDTA, catalase, ascorbate and tocopherol in sperm preparation medium may scavenge ROS and decrease their deleterious effects on spermatozoa but these findings are discussed $[67,68]$.
Another point for consideration is the implication of genital oxidative stress in the sperm DNA fragmentation commonly observed in spermatozoa of infertile men [69]. In fact, significant correlations of seminal ROS levels with DNA damage were reported in many studies $[43,70$, 71]. Moreover, other studies reported an increase in DNA damage in sperm from leucocytospermic samples [53, $72,73]$. Recently, it was suggested a direct implication of leucocytes, as an exogenous factor, in generating DNA base modifications evaluated by the formation of 8oxoguanine, a key biomarker of the oxidative DNA damage [74]. Oxidized DNA bases have increased susceptibility to ROS action which reflects a direct and specific action of ROS on sperm DNA [9,75]. The most recent studies on the origin of sperm DNA damage suggested that there might be a cascade of changes that progress from the induction of oxidative stress and DNA base-pair oxidation to DNA fragmentation and cell death [76].

Nevertheless, it seems that the plasma membrane is less vulnerable to oxidative damage than DNA and sperm with significant oxidative DNA damage and intact membranes could preserve its ability to fertilize oocyte [70]. Many of these embryos developed from spermatozoa with fragmented DNA will unfortunately fail at the blastocyst or early fetal stage $[77,78]$. Thereby, the currently use of mechanical techniques such as Intra Cytoplasmic Sperm Injection (ICSI) to bypass some male factor infertility is unlikely to be the 'best practice' since ROS damaged DNA, frequently induced by seminal leucocytes, will result in poor quality blastocysts and an increase in miscarriage $[9,25]$. Additionally, the patients may be urged to consider antioxidant therapy before undergoing reproductive assistance technique that may reduce DNA damage levels and improve sperm fertility potential [9].

\section{CONCLUSIONS}

Oxidative stress is a major factor in male reproductive disorders because it may impair the physiological function of spermatozoa at the molecular level. Understanding the exact mechanisms, by which oxidative stress develops in semen, will improve the management of semen quality impairment by potential toxic ROS. To establish a treatment strategy of genital oxidative stress in infertile men, we must first specify its origin: seminal leucocytes and/or sperm cells themselves, to guide thereby the optimum therapeutic modalities for male infertility particularly in the context of leucocytospermia.

Progress in assisted reproductive technologies continues to be offered to infertile men, who would otherwise be unable to conceive chances to have their own offspring. However, these "mechanical" procedures are unable to compensate for oxidative damage to sperm DNA. 
In addition, direct treatment of oxidative stress and its source may allow for natural conception.

\section{ACKNOWLEDGEMENTS}

We would like to thank the technicians of the laboratory of Histology-Embryology, Medical school Sfax for their help in semen processing and their technical assistance. We express also our gratitude to the staff of the laboratory of cell culture; Biotechnology institute, Sfax, Tunisia for their help. This work was supported by the Histology Embryology research unit, Medical school Sfax and the Tunisian Ministry of Higher Education, Scientific Research, and Technology.

\section{REFERENCES}

[1] Rahman, K. (2007) Studies on free radicals, antioxidants, and co-factors. Clinical Interventions in Aging, 2, 219236.

[2] Brieger, K., Schiavone, S., Miller Jr., F.J. and Krause, K.H. (2102) Reactive oxygen species: From health to disease. Swiss Medical Weekly, 142, w13659.

http://dx.doi.org/10.4414/smw.2012.13659

[3] Agarwal, A. and Saleh, R.A. (2002) Role of oxidants in male infertility: Rationale, significance, and treatment. Urologic Clinics of North America, 29, 817-827. http://dx.doi.org/10.1016/S0094-0143(02)00081-2

[4] Cocuzza, M., Sikka, S.C., Athayde, K.S. and Agarwal, A. (2007) Clinical relevance of oxidative stress and sperm chromatin damage in male infertility: An evidence based analysis. International braz $j$ urol, 33, 603-621. http://dx.doi.org/10.1590/S1677-55382007000500002

[5] Agarwal, A., Makker, K. and Sharma, R. (2008) Clinical relevance of oxidative stress in male factor infertility: An update. American Journal of Reproductive Immunology, 59, 2-11. http://dx.doi.org/10.1111/j.1600-0897.2007.00559.x

[6] Gharagozloo, P. and Aitken, R.J. (2011) The role of sperm oxidative stress in male infertility and the significance of oral antioxidant therapy. Human Reproduction, 26, 1628-1640. http://dx.doi.org/10.1093/humrep/der132

[7] Agarwal, A. and Said, T.M. (2005) Oxidative stress, DNA damage and apoptosis in male infertility: A clinical approach. BJU International, 95, 503-507.

http://dx.doi.org/10.1111/j.1464-410X.2005.05328.x

[8] Saalu, L.C. (2010) The incriminating role of reactive oxygen species in idiopathic male infertility: An evidence based evaluation. Pakistan Journal of Biological Sciences, 13, 413-422. http://dx.doi.org/10.3923/pjbs.2010.413.422

[9] Tremellen, K. (2008) Oxidative stress and male infertileity-A clinical perspective. Human Reproduction Update, 14, 243-258. http://dx.doi.org/10.1093/humupd/dmn004

[10] Aitken, R.J. and Koppers, A.J. (2011) Apoptosis and DNA damage in human spermatozoa. Asian Journal of Andrology, 13, 36-42. http://dx.doi.org/10.1038/aja.2010.68

[11] Kessopoulou, E., Tomlinson, M.J., Barratt, C.L., Bolton, A.E. and Cooke, I.D. (1992) Origin of reactive oxygen species in human semen: Spermatozoa or leucocytes? The Journal of the Society for Reproduction and Fertility, 94, 463-470. http://dx.doi.org/10.1530/jrf.0.0940463

[12] Sharma, R.K. and Agarwal, A. (1996) Role of reactive oxygen species in male infertility. Urology, 48, 835-850. http://dx.doi.org/10.1016/S0090-4295(96)00313-5

[13] Anderson, D.J. and Politch, J.A. (1996) Evaluation and treatment of the infertile male. In: Centola, G.M. and Ginsburg, K.A., Eds., Cambridge University Press, New York, 263-277.

[14] Depuydt, C.E., Bosmans, E., Zalata, A., Schoonjans, F. and Comhaire, F.H. (1996) The relation between reactive oxygen species and cytokines in andrological patients with or without male accessory gland infection. Journal of Andrology, 17, 699-707.

[15] Keck, C., Gerber-Schäfer, C., Clad, A., Wilhelm, C. and Breckwoldt, M. (1998) Seminal tract infections: Impact on male fertility and treatment options. Human Reproduction Update, 4, 891-903. http://dx.doi.org/10.1093/humupd/4.6.891

[16] World Health Organization (1999) Laboratory manual for the examination of human semen and sperm-cervical mucus interaction. Cambridge University Press, Cambridge.

[17] World Health Organization (2010) Laboratory manual for the examination and processing of human semen. WHO Press, Geneva.

[18] Kashou, A.H., Sharma, R. and Agarwal, A. (2013) Assessment of oxidative stress in sperm and semen. In: Carrell, D.T. and Aston, K.I., Eds., Spermatogenesis: Methods and protocols, Methods in Molecular Biology, Humana Press, New York, 351-361.

[19] Krausz, C., Mills, C., Rogers, S., Tan, S.L. and Aitken, R.J. (1994) Stimulation of oxidant generation by human sperm suspensions using phorbol esters and formyl peptides: Relationships with motility and fertilization in vitro. Fertility and Sterility, 62, 599-605.

[20] Storey, B.T. (1997) Biochemistry of the induction and prevention of lipoperoxidative damage in human spermatozoa. Molecular Human Reproduction, 3, 203-213. http://dx.doi.org/10.1093/molehr/3.3.203

[21] Tomlinson, M.J., Barratt, C.L. and Cooke, I.D. (1993) Prospective study of leukocytes and leukocyte subpopulations in semen suggests they are not a cause of male infertility. Fertility and Sterility, 60, 1069-1075.

[22] Aitken, R.J., Irvine, D.S. and Wu, F.C. (1991) Prospective analysis of sperm-oocyte fusion and reactive oxygen species generation as criteria for the diagnosis of infertility. American Journal of Obstetrics \& Gynecology, 164, 542-551. http://dx.doi.org/10.1016/S0002-9378(11)80017-7

[23] du Plessis, S.S., McAllister, D.A., Luu, A., Savia, J., Agarwal, A. and Lampiao, F. (2010) Effects of $\mathrm{H}_{2} \mathrm{O}_{2}$ exposure on human sperm motility parameters, reactive oxygen species levels and nitric oxide levels. Andrologia, 42, 206-210. http://dx.doi.org/10.1111/j.1439-0272.2009.00980.x

[24] Sharma, R.K., Pasqualotto, A.E., Nelson, D.R., Thomas Jr., A.J. and Agarwal A. (2001) Relationship between seminal white blood cell counts and oxidative stress in 
men treated at an infertility clinic. Journal of Andrology, 22, 575-583.

[25] Barraud-Lange, V., Pont, J.C., Ziyyat, A., Pocate, K., Sifer, C., Cedrin-Durnerin, I., Fechtali, B., Ducot, B. and Wolf, J.P. (2011) Seminal leukocytes are good samaritans for spermatozoa. Fertility and Sterility, 96, 1315-1319. http://dx.doi.org/10.1016/j.fertnstert.2011.09.035

[26] Zini, A. and Sigman, M. (2009) Evaluation of sperm function. In: Lipshultz, L.I., Howards, S.S. and Niederberger, C.S., Eds., Infertility in the Male, Cambridge University Press, New York, 177-198. http://dx.doi.org/10.1017/CBO9780511635656.012

[27] Agarwal, A. and Prabakaran, S.A. (2005) Oxidative stress and antioxidants in male infertility: A difficult balance. Iranian Journal of Reproductive Medicine, 3, 1-8.

[28] Agarwal, A., Sharma, R.K., Nallella, K.P., Thomas Jr., A.J., Alvarez, J.G. and Sikka, S.C. (2006) Reactive oxygen species as an independent marker of male factor infertility. Fertility and Sterility, 86, 878-885. http://dx.doi.org/10.1016/j.fertnstert.2006.02.111

[29] Doshi, S.B., Khullar, K., Sharma, R.K. and Agarwal, A. (2012) Role of reactive nitrogen species in male infertileity. Reproductive Biology and Endocrinology, 10, 109. http://dx.doi.org/10.1186/1477-7827-10-109

[30] Sikka, S.C. (2004) Role of oxidative stress and antioxidants in andrology and assisted reproductive technology. Journal of Andrology, 25, 5-18.

[31] Ochsendorf, F.R., Thiele, J., Fuchs, J., Schuttau, H., Freisleben, H.J., Buslau, M. and Milbradt, R. (1994) Chemiluminescence in semen of infertile men. Andrologia, 26, 289-293.

http://dx.doi.org/10.1111/j.1439-0272.1994.tb00804.x

[32] Williams, A.C. and Ford, W.C. (2005) Relationship between reactive oxygen species production and lipid peroxidation in human sperm suspensions and their association with sperm function. Fertility and Sterility, 83, 929936. http://dx.doi.org/10.1016/j.fertnstert.2004.11.031

[33] Athayde, K.S., Cocuzza, M., Agarwal, A., Krajcir, N., Lucon, A.M., Srougi, M. and Hallak, J. (2007) Development of normal reference values for seminal reactive oxygen species and their correlation with leukocytes and semen parameters in a fertile population. Journal of Andrology, 28, 613-620.

http://dx.doi.org/10.2164/jandrol.106.001966

[34] Plante, M., de Lamirande, E. and Gagnon, C. (1994) Reactive oxygen species released by activated neutrophils, but not by deficient spermatozoa, are sufficient to affect normal sperm motility. Fertility and Sterility, 62, 387393.

[35] Griveau, J.F. and Le Lannou, D. (1997) Reactive oxygen species and human spermatozoa: Physiology and pathology. International Journal of Andrology, 20, 61-69. http://dx.doi.org/10.1046/j.1365-2605.1997.00044.x

[36] Armstrong, J.S., Rajasekaran, M., Chamulitrat, W., Gatti, P., Hellstrom, W.J. and Sikka, S.C. (1999) Characterization of reactive oxygen species induced effects on human spermatozoa movement and energy metabolism. Free Radical Biology and Medicine, 26, 869-880. http://dx.doi.org/10.1016/S0891-5849(98)00275-5
[37] Baumber, J., Ball, B.A., Gravance, C.G., Medina, V. and Davies-Morel, M.C. (2000) The effect of reactive oxygen species on equine sperm motility, viability, acrosomal integrity, mitochondrial membrane potential, and membrane lipid peroxidation. Journal of Andrology, 21, 895902.

[38] Wang X., Sharma, R.K., Gupta, A., George, V., Thomas, A.J., Falcone, T. and Agarwal, A. (2003) Alterations in mitochondria membrane potential and oxidative stress in infertile men: A prospective observational study. Fertility and Sterility, 80, 844-850.

http://dx.doi.org/10.1016/S0015-0282(03)00983-X

[39] Agarwal, A., Saleh, R.A. and Bedaiwy, M.A. (2003) Role of reactive oxygen species in the pathophysiology of human reproduction. Fertility and Sterility, 79, 829-843. http://dx.doi.org/10.1016/S0015-0282(02)04948-8

[40] Aitken, R.J., Wingate, J.K., De Iuliis, G.N., Koppers, A.J. and McLaughlin, E.A. (2006) Cis-unsaturated fatty acids stimulate reactive oxygen species generation and lipid peroxidation in human spermatozoa. The Journal of Clinical Endocrinology \& Metabolism, 91, 4154-4163.

http://dx.doi.org/10.1210/jc.2006-1309

[41] de Lamirande, E. and Gagnon, C. (1992) Reactive oxygen species and human spermatozoa. I. Effects on the motility of intact spermatozoa and on sperm axonemes. Journal of Andrology, 13, 368-378.

[42] Tavilani, H., Doosti, M. and Saeidi, H. (2005) Malondialdehyde levels in sperm and seminal plasma of asthenozoospermic and its relationship with semen parameters. Clinica Chimica Acta, 356, 199-203. http://dx.doi.org/10.1016/j.ccen.2005.01.017

[43] Kothari, S., Thompson, A., Agarwal, A. and du Plessis, S.S. (2010) Free radicals: Their beneficial and detrimental effects on sperm function. Indian Journal of Experimental Biology, 48, 425-435.

[44] Aitken, R.J., Buckingham, D., West, K.M., Wu, F.C., Zikopoulos, K. and Richardson, D.W. (1992) Differential contribution of leucocytes and spermatozoa to the generation of reactive oxygen species in the ejaculates of oligozoospermic patients and fertile donors. The Journal of the Society for Reproduction and Fertility, 94, 451-462. http://dx.doi.org/10.1530/jrf.0.0940451

[45] Zalata, A., Hafez, T. and Comhaire, F. (1995) Evaluation of the role of reactive oxygen species in male infertility. Human Reproduction, 10, 1444-1451. http://dx.doi.org/10.1093/HUMREP/10.6.1444

[46] Pasqualotto, F.F., Sharma, R.K., Nelson, D.R., Thomas, A.J. and Agarwal, A. (2000) Relationship between oxidative stress, semen characteristics, and clinical diagnosis in men undergoing infertility investigation. Fertility and Sterility, 73, 459-464. http://dx.doi.org/10.1016/S0015-0282(99)00567-1

[47] Boonstra, J. and Post, J.A. (2004) Molecular events associated with reactive oxygen species and cell cycle progression in mammalian cells. Gene, 337, 1-13. http://dx.doi.org/10.1016/j.gene.2004.04.032

[48] Tvrdá, E., Kňažická, Z., Bárdos, L., Massányi, P. and Lukáč, N. (2011) Impact of oxidative stress on male fertility_A review. Acta Veterinaria Hungarica, 59, 465-484. 
http://dx.doi.org/10.1556/AVet.2011.034

[49] Ochsendorf, F.R. (1999) Infections in the male genital tract and reactive oxygen species. Human Reproduction Update, 5, 399-420.

http://dx.doi.org/10.1093/humupd/5.5.399

[50] Fraczek, M. and Kurpisz, M. (2007) Inflammatory mediators exert toxic effects of oxidative stress on human spermatozoa. Journal of Andrology, 28, 325-333. http://dx.doi.org/10.2164/jandrol.106.001149

[51] Villegas, J., Schulz, M., Soto, L., Iglesias, T., Miska, W. and Sánchez, R. (2005) Influence of reactive oxygen species produced by activated leukocytes at the level of apoptosis in mature human spermatozoa. Fertility and Sterility, 83, 808-810. http://dx.doi.org/10.1016/j.fertnstert.2004.09.022

[52] Wang, A., Fanning, L., Anderson, D.J. and Loughlin, K.R. (1997) Generation of reactive oxygen species by leukocytes and sperm following exposure to urogenital tract infection. Archives of Andrology, 39, 11-17. http://dx.doi.org/10.3109/01485019708987896

[53] Saleh, R.A., Agarwal, A., Kandirali, E., Sharma, R.K., Thomas, A.J., Nada, E.A., Evenson, D.P. and Alvarez, J.G. (2002) Leukocytospermia is associated with increased reactive oxygen species production by human spermatozoa. Fertility and Sterility, 78, 1215-1224. http://dx.doi.org/10.1016/S0015-0282(02)04237-1

[54] Krausz, C., West, K., Buckingham, D. and Aitken, R.J. (1992) Development of a technique for monitoring the contamination of human semen samples with leukocytes. Fertility and Sterility, 57, 1317-1325.

[55] Sukcharoen, N., Keith, J., Irvine, D.S. and Aitken, R.J. (1996) Prediction of the in-vitro fertilization (IVF) potential of human spermatozoa using sperm function tests: The effect of the delay between testing and IVF. Human Reproduction, 11, 1030-1034.

http://dx.doi.org/10.1093/oxfordjournals.humrep.a019291

[56] Gomez, E., Buckingham, D.W., Brindle, J., Lanzafame, F., Irvine, D.S. and Aitken, R.J. (1996) Development of an image analysis system to monitor the retention of residual cytoplasm by human spermatozoa: Correlation with biochemical markers of the cytoplasmic space, oxidative stress, and sperm function. Journal of Andrology, 17, 276-287.

[57] Said, T.M., Agarwal, A., Sharma, R.K., Thomas Jr., A.J. and Sikka, S.C. (2005) Impact of sperm morphology on DNA damage caused by oxidative stress induced by betanicotinamide adenine dinucleotide phosphate. Fertility and Sterility, 83, 95-103. http://dx.doi.org/10.1016/j.fertnstert.2004.06.056

[58] Fisher, H.M. and Aitken, R.J. (1997) Comparative analysis of the ability of precursor germ cells and epididymal spermatozoa to generate reactive oxygen metabolites. Journal of Experimental Zoology, 277, 390-400. http://dx.doi.org/10.1002/(SICI)1097-010X(19970401)27 7:5<390::AID-JEZ5>3.0.CO;2-K

[59] Said, T.M., Agarwal, A., Sharma, R.K., Mascha, E., Sikka, S.C. and Thomas Jr., A.J. (2004) Human sperm superoxide anion generation and correlation with semen quality in patients with male infertility. Fertility and Ste- rility, 82, 871-877.

http://dx.doi.org/10.1016/j.fertnstert.2004.02.132

[60] Pasqualotto, F.F., Sharma, R.K., Kobayashi, H., Nelson, D.R., Thomas Jr., A.J. and Agarwal, A. (2001) Oxidative stress in normospermic men undergoing infertility evaluation. Journal of Andrology, 22, 316-322.

[61] Agarwal, A., Ikemoto, I. and Loughlin, K.R. (1994) Effect of sperm washing on levels of reactive oxygen species in semen. Archives of Andrology, 33, 157-162. http://dx.doi.org/10.3109/01485019408987819

[62] Fingerova, H., Oborna, I., Novotny, J., Svobodova, M., Brezinova, J. and Radova, L. (2009) The measurement of reactive oxygen species in human neat semen and in suspended spermatozoa: A comparison. Reproductive Biology and Endocrinology, 7, 118. http://dx.doi.org/10.1186/1477-7827-7-118

[63] Venkatesh, S., Shamsi, M.B., Dudeja, S., Kumar, R. and Dada, R. (2011) Reactive oxygen species measurement in neat and washed semen: Comparative analysis and its significance in male infertility assessment. Archives of Gynecology and Obstetrics, 283, 121-126. http://dx.doi.org/10.1007/s00404-010-1645-4

[64] Hughes, C.M., Lewis, S.E., McKelvey-Martin V.J. and Thompson, W. (1998) The effects of antioxidant supplementation during percoll preparation on human sperm DNA integrity. Human Reproduction, 13, 1240-1247. http://dx.doi.org/10.1093/humrep/13.5.1240

[65] Donnelly, E.T., McClure, N. and Lewis, S.E. (1999) The effect of ascorbate and alpha-tocopherol supplementation in vitro on DNA integrity and hydrogen peroxide-induced DNA damage in human spermatozoa. Mutagenesis, 14, 505-512. http://dx.doi.org/10.1093/mutage/14.5.505

[66] Chi, H.J., Kim, J.H., Ryu, C.S., Lee, J.Y., Park, J.S., Chung, D.Y., Choi, S.Y., Kim, M.H., Chun, E.K. and Roh, S.I. (2008) Protective effect of antioxidant supplementation in sperm-preparation medium against oxidative stress in human spermatozoa. Human Reproduction, 23, 1023-1028. http://dx.doi.org/10.1093/humrep/den060

[67] Donnelly, E.T., McClure, N. and Lewis, S.E. (2000) Glutathione and hypotaurine in vitro: Effects on human sperm motility, DNA integrity and production of reactive oxygen species. Mutagenesis, 15, 61-68. http://dx.doi.org/10.1093/mutage/15.1.61

[68] Baumber, J., Ball, B.A. and Linfor, J.J. (2005) Assessment of the cryopreservation of equine spermatozoa in the presence of enzyme scavengers and antioxidants. American Journal of Veterinary Research, 66, 772-779. http://dx.doi.org/10.2460/ajvr.2005.66.772

[69] Mahfouz, R., Sharma, R., Thiyagarajan, A., Kale, V., Gupta, S., Sabanegh, E. and Agarwal, A. (2010) Semen characterristics and sperm DNA fragmentation in infertile men with low and high levels of seminal reactive oxygen species. Fertility and Sterility, 94, 2141-2146. http://dx.doi.org/10.1016/j.fertnstert.2009.12.030

[70] Aitken, R.J. and Krausz, C. (2001) Oxidative stress, DNA damage and the Y chromosome. Reproduction, 122, 497506. http://dx.doi.org/10.1530/rep.0.1220497

[71] Aitken, R.J. and De Iuliis, G.N. (2007) Origins and consequences of DNA damage in male germ cells. Repro- 
ductive BioMedicine Online, 14, 727-733. http://dx.doi.org/10.1016/S1472-6483(10)60676-1

[72] Alvarez, J.G., Sharma, R.K., Ollero, M., Saleh, R.A., Lopez, M.C., Thomas, A.J. Jr., Evenson, D.P. and Agarwal, A. (2002) Increased DNA damage in sperm from leukocytospermic semen samples as determined by the sperm chromatin structure assay. Fertility and Sterility, 78, 319-329. http://dx.doi.org/10.1016/S0015-0282(02)03201-6

[73] Erenpreiss, J., Hlevicka, S., Zalkalns, J. and Erenpreisa J. (2002) Effect of leukocytospermia on sperm DNA integrity: A negative effect in abnormal semen samples. Journal of Andrology, 23, 717-723.

[74] Zribi, N., Chakroun, N.F., Elleuch, H., Abdallah, F.B., Ben Hamida, A.S., Gargouri, J., Fakhfakh, F. and Keskes, L.A. (2011) Sperm DNA fragmentation and oxidation are independent of malondialdheyde. Reproductive Biology and Endocrinology, 9, 47-54. http://dx.doi.org/10.1186/1477-7827-9-47

[75] Makker, K., Agarwal, A. and Sharma, R. (2009) Oxida- tive stress and male infertility. Indian Journal of Medical Research, 129, 357-367.

[76] Aitken, R.J., De Iuliis, G.N., Finnie, J.M., Hedges, A. and McLachlan, R.I. (2010) Analysis of the relationships between oxidative stress, DNA damage and sperm vitality in a patient population: Development of diagnostic criteria. Human Reproduction, 25, 2415-2426. http://dx.doi.org/10.1093/humrep/deq214

[77] Muriel, L., Garrido, N., Fernández, J.L., Remohí, J., Pellicer, A., de los Santos, M.J. and Meseguer, M. (2006) Value of the sperm deoxyribonucleic acid fragmentation level, as measured by the sperm chromatin dispersion test, in the outcome of in vitro fertilization and intracytoplasmic sperm injection. Fertility and Sterility, 85, 371-383. http://dx.doi.org/10.1016/j.fertnstert.2005.07.1327

[78] Avendaño, C., Franchi, A., Duran, H. and Oehninger S. (2010) DNA fragmentation of normal spermatozoa negatively impacts embryo quality and intracytoplasmic sperm injection outcome. Fertility and Sterility, 94, 549-557. http://dx.doi.org/10.1016/j.fertnstert.2009.02.050

SD: Standard Deviation

RLU: Relative Light Units

HBSS: Hank's Balanced Salt Solution

NADPH: Nicotinamide Adenine Dinucleotide Phosphate G6PD: Glucose-6-Phosphate Dehydrogenase

ICSI: Intra Cytoplasmic Sperm Injection 